\title{
Forced Mobility and Immobility in a Turbulent World
}

\author{
I. P. Tsapenko*,**,\# \\ Primakov National Research Institute of the World Economy and International Relations, Russian Academy of Sciences, \\ Moscow, Russia \\ *e-mail: tsapenko@bk.ru \\ **e-mail: tsapenko@imemo.ru
}

Received May 10, 2021; revised May 25, 2021; accepted June 2, 2021

\begin{abstract}
Forced mobility and forced immobility are not just polar types of involuntary migration behavior. According to the author, they are closely interconnected and are like communicating vessels, being a product of common causes: conflict, violence, and unfavorable environmental processes, the action of which can be both stimulating and hindering movement. The decision to leave or stay is influenced by a wide range of objective factors and subjective circumstances, including values, preferences, emotions, irrationality, etc. The growing social instability and disadvantages are reflected in an increased scale of forced displacements and an increased share of refugees among migrants, which indicates an increase in the forced nature of modern migration. The proliferation of hot spots of conflicts and disasters increases the risk of falling into the traps of immobility for people who do not have resources for migration. Comprehensive solutions and joint action by states and other interested parties can help improve protection and support for those affected by political and natural disasters. There is a trend towards extending aid to broader needy groups.
\end{abstract}

Keywords: conflicts and persecution, natural disasters and climate change, COVID-19 pandemic, forced mobility, refugees, internally displaced persons, forced immobility, stranded populations, comprehensive solutions and joint actions to protect and support victims of political and natural disasters.

DOI: $10.1134 / \mathrm{S} 1019331621050099$

The modern world is undergoing dramatic transformations-large scale, deep, and dynamic. At the same time, the changes and acceleration that have marked our century are often accompanied by an increase in social instability and distress. According to the report on the Global Peace Index 2020, compiled by the Australian Institute for Economics and Peace, since 2008 the planet has seen an increase in conflict, violence, and adverse environmental processes, accompanied by a deterioration in the security of living conditions. In the years 2011-2019, the number of events of civil unrest and riots in the world more than tripled, including by nine times in Africa. Natural disasters occur now three times more often than four decades ago [1]. The consequences of these cataclysms are exacerbated by the COVID-19 pandemic and the resulting economic crisis.

During a period of turbulence, serious shifts also occur in the field of human movements, transforming the migration agenda, including the policies of states

\footnotetext{
\# Irina Pavlovna Tsapenko is a Sector Head at the Primakov National Research Institute of the World Economy and International Relations (IMEMO), RAS.
}

and their unions, human rights, social inequality, values and attitudes, etc. As highlighted in the World Migration Report 2020 by the International Organization for Migration (IOM), such changes are prompting migration researchers to update their research topics and revise previous approaches [2].

Not so long ago, at the turn of the century, scientists and politicians used to focus on the unprecedented increase in the scale of cross-border migration-the movement of people changing their countries of habitual residence. The spread of short-term nonmigration movements of the population led to the expansion of the subject of research and the use of the term mobility to characterize new realities in this area. At the same time, the growing instability and trouble in the world and the appearance of unfavorable, abnormal, and appearance life situations and conditions increase the effect of negative factors pushing people out of their homes or, conversely, hindering movement. We mean forced (or inviluntary) mobility 
and immobility. ${ }^{1}$ The topicality and significance of the problem of forced migration behavior has sharply increased and has been especially vivid in the conditions of freezing flows, or the "mobility crisis" caused by the COVID-19 pandemic.

This article is dedicated to the forced migration behavior of people, interpreted in a broad sense of this term. It includes not only involuntary movements of the population, primarily refugees, but also a much less noticeable and less known but no less extreme form of such behavior-the forced territorial immobility of people trapped in political and natural disasters.

What is meant by forced mobility and immobility? What are the factors and mechanisms of forced migration behavior? What are the trends in the field of mobility? How does the COVID-19 pandemic affect them? What changes are taking place in the protection system for people affected by conflicts and natural disasters? These issues will be the focus of this work, which is based on an analysis of available theoretical research and statistical information from various sources.

\section{FORCED DISPLACEMENTS: COSTS AND ADAPTATION RESOURCE}

Territorial mobility is a natural feature and an integral part of modern life, metaphorically and very aptly termed by the British sociologist Z. Bauman as liquid (due to incessant migration and other flows). Another British sociologist, J. Urry, looking at the world through the prism of flows, noted that for the rich and even for the poor, movement had come to mean "a way of life across the globe" [3].

However, it is clear that not all mobility is normal and voluntary. Statistics show that mobility is increasingly becoming a way of survival, forced. In the scientific literature, the term forced (or involuntary) mobility is used as an umbrella for characterizing human flows in which there is an element of coercion, including the threat to life, health, and freedom as a result of political persecution and conflicts or natural or anthropogenic disasters. However, the division of mobility into voluntary and forced is partly conditional and arbitrary. Thus, migration caused by the pressure of unfavorable socioeconomic circumstances, in particular mass unemployment, poverty, etc., that is, in fact, forced, is formally considered voluntary. Moreover, the multiplicity of reasons for the displacement of people from country to country makes it difficult to distinguish between them clearly.

\footnotetext{
${ }^{1}$ As noted in the 2009 Council of Europe Assembly Resolution No. 1655, paragraph 2, "natural disasters and environmental degradation will increasingly determine the nature of human mobility as well as its humanitarian and security dimensions, which will need to be urgently assessed." (https://www.coe.int/T/r/Parliamentary_Assembly/\%5bRussian_docu-

ments\%5d/\%5b2009\%5d/\%5bJan2009\%5d/Res1655_rus.asp).
}

Therefore, the territorial mobility of the population is sometimes presented as a kind of continuum of different types of displacements-from completely voluntary to completely forced [2, p. 256].

Until recently, the concept of forced migrations had hardly been developed. The Swiss economist E. Piguet explains this by the dominance of the economic paradigm in migration research. The construction of migration theories, as a rule, boiled down to the definition of certain patterns of human movement, when deciding about which potential migrants retained greater freedom of choice and were not forced to move [4]. This approach was initiated by the British geographer E. Ravenstein, who proposed the so-called laws of migration. When considering migration as an economic phenomenon and explaining its causes, mechanisms, and consequences from the standpoint of economic determinism, refugees from armed conflicts, environmental disasters, etc., were usually not taken into account. As noted by the American political scientist and migration historian A. Zolberg, the spontaneity, uniqueness of the development of events, and the unpredictability of its options inherent in this type of movement make them of little use for theoretical analysis (cited by [4]).

Meanwhile, more than half a century ago, the American functionalist sociologist E. Lee presented migration as a result of push and pull factors (including political and natural). According to the British and Australian researcher S. Castles, the former vision of flight as a chain of unrelated emergencies is giving way to judging it as an integral part of North-South relations [5, p. 17], emerging in the process of globalization and associated with huge gaps in the development of individual countries and regions and acute social inequality in lagging territories. Meanwhile, social inequality, as is known, is often accompanied by political instability and conflict, human rights violations, persecution, etc. Added to this are anthropogenic disasters and unfavorable climate changes provoked by the irresponsible economic activities of large corporations, especially in newly developed economic spaces. Population movements, stimulated by social transformations and stratification and political and ecological cataclysms, which are collectively defined as mixed migration, fit organically into the framework of migration theory $[6,7]$ and the more voluminous conceptual frameworks of the world systems of I. Wallerstein, the globalization of S. Sassen, and other historical and structuralist constructions.

Moreover, in recent decades, the development of the interdisciplinary approach to the study of crossborder migration has made it possible to consider forced movements from the positions and in the categories of different sciences as a multidimensional social process. Obviously, there is a relationship between the level of political and environmental distress and the intensity of forced flows; however, as 
studies show, such a relationship is usually nonlinear. The decision whether to leave or stay, regardless of the risks, is made with account for a number of circumstances [2]. The propensity, motivation, and readiness to migrate can be influenced by both objective and subjective, personal factors, and they can be both long term or can arise as a result of a sudden urge (push). If we consider forced mobility and immobility as two sides of the same phenomenon, we can build a ramified system of determinants, causes, and conditions that affect the migration behavior of the population. Note that forced displacements can be interpreted in a broad political and economic context as a type of relations between citizens and the state, when people retain a certain autonomy in making a migration decision and, to a degree, control the routes and methods of their movement [4]. Considering that it is possible to leave dangerous territories only under certain conditions, such movements, with all their costs for migrants and host communities, have the properties of a saving migration resource and an important element of an adaptation strategy [8], to which, in fact, humankind has turned since time immemorial.

Such an interpretation of forced migrations introduces certain elements of choice and voluntariness into their model, which provides a basis for identifying rules and constructing schemes. However, this in no way changes the forced nature of such flows, which is very aptly reflected in the concept of survival migration of the British political scientist A. Betts [9]. First of all, this applies to refugees, who, according to international law, ${ }^{2}$ are persons leaving their homelands because of a serious threat to their life, physical integrity, or freedom as a result of persecution, armed conflict, violence, or major public disorder.

UN statistics show that behind the seemingly stable progressive dynamics of the global number of international migrants, which increased over the first twenty years of this century from 173 million to 281 million (primarily owing to an increase in the number of foreign workers and reunited family members), there is a significant variability in flows in emergency and other abnormal situations. Since the mid-2000s, in the context of increasing political instability and conflict, it is forced displacements, especially from the poorest countries, that have increased in relative terms most intensively, giving rise to acute migration crises in Europe and North America in the 2010s. In the years 2005-2020, the average annual growth rate of the global number of refugees and asylum seekers was $5.5 \%$, while that of all migrants was $2.5 \%$ (calculated

\footnotetext{
2 The 1951 UN Geneva Convention Relating to the Status of Refugees, which is the fundamental (along with the 1967 Protocol) document in this area, defines a refugee as a person who, "owing to well-founded fear of being persecuted for reasons of race, religion, nationality, membership of a particular social group, or political opinion, is outside the country of his nationality and is unable or, owing to such fear, is unwilling to avail himself of the protection of that country" (Article 1).
}

from [10]). As a result, the number of refugees and asylum seekers has more than doubled since 2000 , reaching almost 34 million in 2020. The share of this category in the total number of international migrants increased from $9.5 \%$ in 2000 to $12 \%$ in 2020 [10]. In poor countries of destination, which cannot provide acceptable conditions for the deployment of such massive contingents, this figure reaches $50 \%$.

Since the end of the 20th century, the growing attention of researchers, politicians, and the public has been attracted by environmental migrations. However, despite the large array of works devoted to this topic, a universally accepted concept of environmental migrant has not yet been formed, and a large number of terms are used in the scientific, in particular, English-language literature (environmental migrant, environmental refugee, climate refugee, environmentally induced migrant, environmentally motivated migrant, etc. [11]).

A report of the United Nations Environment Program (UNEP) explicitly states that environmental degradation drives human displacement, "threatening lives and making people's livelihoods untenable" $[12$, p. 70]. Serious migration challenges are associated with the aggravation of food security problems, a shortage of drinking water, and the risks of loss of habitats. The International Organization for Migration defines environmental migration more broadly, as "the movement of persons or groups of persons who, predominantly for reasons of sudden or progressive changes in the environment that adversely affect their lives or living conditions, are forced to leave their places of habitual residence, or choose to do so, either temporarily or permanently" [13, p. 65]. Among the sudden factors are natural (droughts, cyclones, storms, and floods) and anthropogenic disasters that generate flows of urgently fleeing migrants; among the progressive factors are unfavorable changes in climatic conditions and habitat, including desertification, deforestation, soil erosion, sea level rise, etc., which force people to leave or induce and motivate them to search for a better place to live [14, p. 165].

The importance of sudden and pulsating threats from epidemics of previously unknown diseases is increasing, which corresponds to the concept of an epidemiologic transition. The increase in biohazard caused by COVID-19 and decrease in the comfort of the living environment are forcing people to leave not only countries with high incidence of coronavirus but also to move from large cities to rural areas with a more favorable epidemiological situation. In the latter case, we can talk about the phenomenon of deurbanization. At the same time, the pandemic provoked nontypical forced flows: massive, hasty repatriation of people who feared to be stranded abroad due to a lockdown, including illegal return flows, for example, of Moroccans living in Spain or Thais working in Myanmar. 


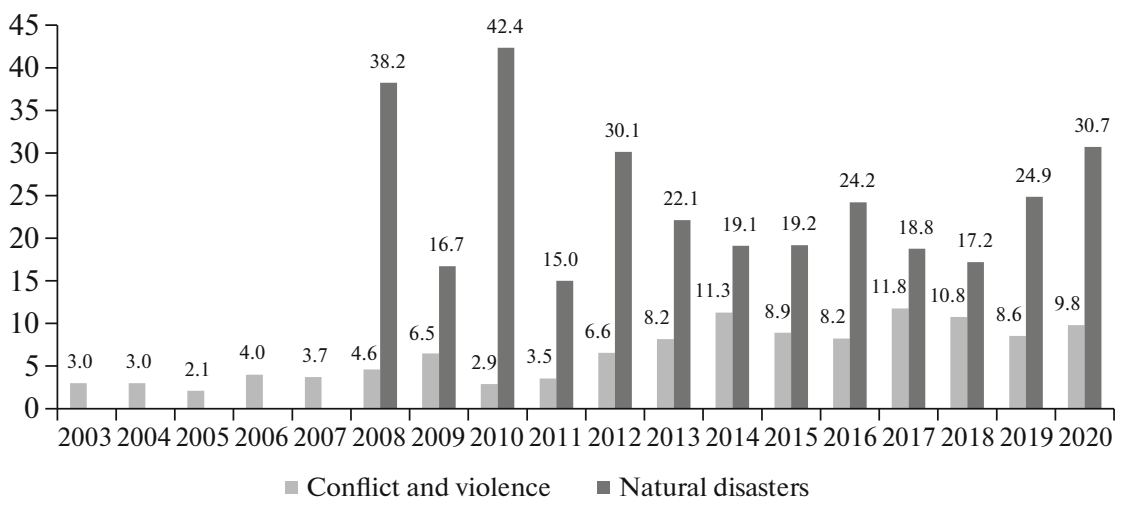

Fig. 1. Number of newly displaced persons as a result of conflicts, violence, and natural disasters during the year, 2003-2020, mln people. Compiled according to [16].

The terminological confusion in the field of environmental migrations is reflected in the lack of reliable and regular statistics. It is especially difficult to track movements caused by gradual climate change. Given that forced migration is often limited to a short period and relatively short distances, the main focus is on assessing the scale of internal displacement. ${ }^{3}$

Data from the Internal Displacement Monitoring Center (IDMC) indicate that environmental disasters are more likely to force people to change their habitat than political distress. The number of people newly displaced within a country in 2020 (the number of new cases of displacement per year) reached $40.5 \mathrm{mln}$-the highest level after 2011. Most of them-30.7 mln-left their homes because of natural disasters or were evacuated before them (primarily in China, the Philippines, Bangladesh, India, and the United States); many fewer $(9.8 \mathrm{mln})$, because of conflicts and violence (primarily in the Democratic Republic of the Congo, Syria, Ethiopia, Mozambique, and Burkina Faso) (Fig. 1). Sometimes the effects of these two factors are superimposed on one another. Thus, the inhabitants of Somalia and Yemen who had left their places because of interethnic conflicts were forced by natural disasters to new displacements. Similar reasons often motivate people in the post-Soviet space [15]. In 2020, massive displacements in the region were caused by floods in Uzbekistan and Kazakhstan and the Armenian-Azerbaijani conflict over Nagorno-Karabakh (with a temporary lull in hostilities in Ukraine).

The impact of natural disasters is usually (but by no means always) more short-lived, which allows people

\footnotetext{
${ }^{3}$ According to the 1998 UN Guiding Principles on Internal Displacement, "...internally displaced persons are persons or groups of persons who have been forced or obliged to flee or to leave their homes or places of habitual residence, in particular as a result of or in order to avoid the effects of armed conflict, situations of generalized violence, violations of human rights, or natural or human-made disasters, and who have not crossed an internationally recognized State border.”
}

to return to their native places as such disasters end and their consequences are eliminated, in contrast to the protracted nature of many political conflicts or the prolonged stay of nondemocratic regimes in power, which prevents the reverse movement home and often forces them to make secondary, including cross-border, migrations. As a result, the cumulative (accumulated) number of people who have ever been displaced due to political reasons and who are unable to return to their former place is regularly, almost from year to year, replenished with new contingents and significantly exceeds similar cohorts living far from home because of environmental disasters. Of the 55 million global internally displaced persons accumulated by the end of 2020, 48 million were not living in their homelands due to conflict and violence (maximum after 1990), while due to natural disasters, global records of which began to be kept only since 2019, seven million were outside the traditional areas (Fig. 2). Considering the current tendency towards increased conflict in the world, we can expect an intensification of population movements caused by this process. A similar scenario worked out by the expert community appears among the main options for the development of migration in the coming decades [17].

In connection with the increase in the intensity of extreme weather events, scientists predict a huge increase in the scale of environmental migrations. At the same time, their assessments, which were initiated by the British ecologist N. Myers in the early 1990s, differ significantly. Thus, according to the forecasts of the World Bank, by 2050, internal displacements caused by climatic factors will involve 143 million people, including 86 million in tropical Africa, 40 million in South Asia, and 17 million in Latin America [18]. According to the Institute for Economics and Peace, 1.2 billion people live in countries with a high risk of natural disasters and low resistance to them, in particular with a low level of peacefulness, which suggests a high probability of migration of residents of these territories [1]. However, the accuracy of such assess- 


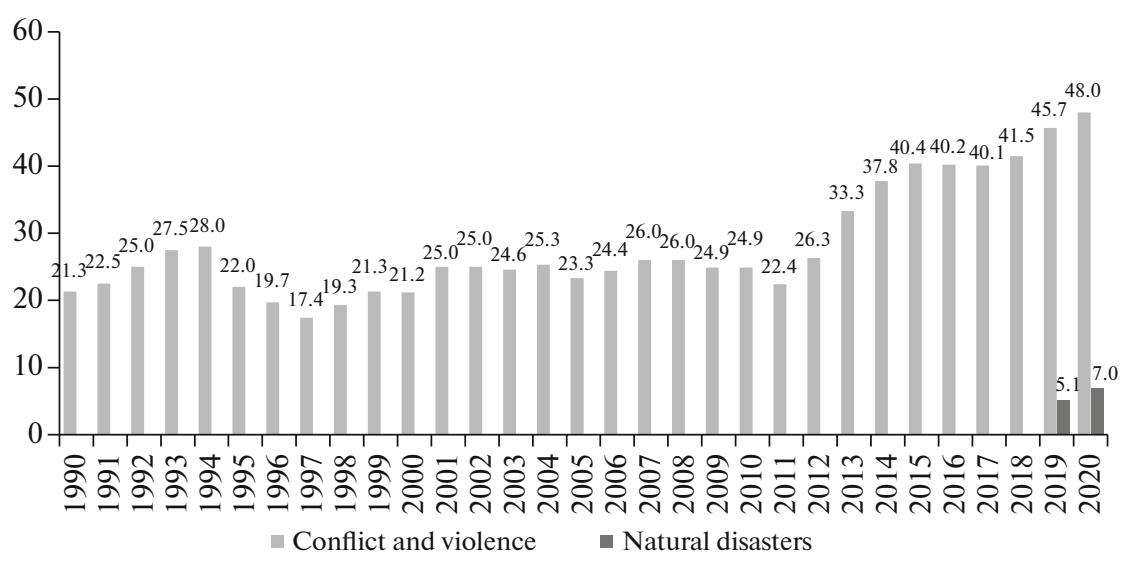

Fig. 2. Cumulative (accumulated) number of previously displaced persons as a result of conflicts, violence, and natural disasters who continue to be forced to stay away from home, at the end of the year, 2003-2019, mln people. Compiled according to [16].

ments arouses a certain skepticism in the academic community, associated, among other things, with the underestimation of nonmigration adaptation measures in modeling flows.

The modern world is experiencing an increase in migrations caused by abnormal situations. Spontaneous population movements increase the vulnerability of the people affected by them, burden the host territories with costs and problems, and require a managerial and legal response. At the same time, migration, even if forced, allows avoiding dangerous situations and thus represents an active response to environmental and political stressors, in contrast to immobility.

\section{TRAPS OF FORCED IMMOBILITY}

At the beginning of this century, the Norwegian social geographer J. Carling drew attention to the fact that there are many times fewer international migrants than those who did not change their permanent place of residence [19]. That is, immobility is a more common condition than cross-border mobility. This, in particular, is evidenced by the fact that foreign tourists are a clear minority in relation to the majority of people who do not make such trips.

The issues of mobility limitations were raised in the classical theories of migration. Thus, in the abovementioned theory of migration of Lee, along with the push and pull factors, factors that hinder and restrain movement are also considered, including the lack of transport links, as well as legal restrictions. However, until recently, migration research was dominated by the "metanarrative of nomadism," which did not fit the topic of immobility that remained on the periphery of scientific research [20].

The Dutch researcher K. Schewel defines immobility as the spatial continuity of an individual's stay in the center of his/her gravitation, or his/her place of residence, for a certain period [20]. The area in which the individual is constantly located, without crossing the boundaries of this space, can be a locality, region, country, continent. The territorial ranking of immobility gives this state a relative character: persons considered to be immobile on an international or interregional scale remain mobile at the local level. Even in conditions of strict anticoronavirus restrictions, people were able to move around at least within the neighborhoods of their residence.

Note that immobility has different, including intermediate, forms that can flow into each other, as well as into mobility. Carling, considering the migration behavior of people from the point of view of opportunities and desire to move, distinguishes, by analogy with voluntary and forced mobility, two main types of immobility. First, there is voluntary immobility, when individuals or groups have opportunities but no desire to change their habitat; such immobility can mean both the success and prospects of life in a certain place and the lack of interest and motivation to move. Second, forced (or involuntary) immobility, which is formed against the background of the need and desirability of moving to another territory in the absence of the necessary opportunities for this [19]. With regard to conflicts and natural disasters, it is not permanent immobility, synonymous with settled life, that is considered but temporary immobility caused by certain cataclysms. Population groups forced to remain in the same place during crises are called trapped. ${ }^{4}$ The Dutch researcher H. de Haas writes about a third form of such behavior, designating it as acquiescent immobility, when there is neither desire nor opportunity to change habitat, which is associated with indifference and doom [22, p. 32].

Thanks to research in the field of immobility, the once widespread idea of the predominantly rational nature and economic conditionality of migration

\footnotetext{
${ }^{4}$ This term was introduced into scientific circulation in 2011 in a report on the Foresight project, implemented under the auspices of the UK Government Office for Science [21, p. 15].
} 
behavior is giving way to a more complex understanding of it. The role of noneconomic values, irrationality, and emotions (attachment of a person to his/her microcosm, fear of the unknown, fear of risks, and problems associated with moving, etc.) when deciding not to move even in extraordinary conditions is recognized.

The existence of two opposite strategies of the migration response to political and natural disastersdeparture or life in the same place-indicates that negative social and environmental events can not only generate and intensify forced flows of migrants but also create obstacles to the movement of people. A survey of Syrian refugees found a time lag (timing effect) in the decision to leave under martial law, which is associated with the wait-and-see strategy. Unlike people who have never been subjected to violence or restrictions on their rights and who seek to leave even before the onset of immediate danger, persecution victims often decide to leave their place only after repeated attempts on the freedom and life of themselves or their family members. A serious immobilizing factor is the difficulty of getting out of the zone of conflicts and repression since, at the borders of such areas and on the main routes of movement of refugees, militants may ambush them [23].

The use of mobility as a lifesaver can be impeded by material, physical, political, psychological, social, and cultural circumstances [24]. These include a lack of financial resources and social contacts; the absence of vehicles or communications; remoteness of the boundaries of the danger zone; being at certain stages of the life cycle; limited physical capabilities; and restrictive migration policies, including refusal of permission to enter, detention, and deportation. A combination of different obstacles of this kind increases their effect.

Mobility acts as a powerful stratifying factor, being, rather, a privilege of the few and not a common good, the lack of access to which symbolizes deprivation [20]. The victims of social conflicts and natural disasters are mainly the poor and the most vulnerable. The example of the recent war in Syria shows that wealthy people with status and connections were the first to leave the country. A similar situation occurred in the case of Hurricane Katrina in New Orleans (United States) in 2005. People who had the resources to move left the dangerous territories ahead of time. The poor, deprived of such funds, primarily African Americans, the elderly, and residents without cars, remained at home, where they were caught in the flood.

Moreover, forced immobility exacerbates people's vulnerability to other circumstances, aggravating their situation [25]. Damage is caused not only to the physical well-being but also to the peace of mind of people who suffer from a feeling of hopelessness, infringement of self-esteem, and unsteady identity [24]. (At the same time, the phenomenon of personal growth in response to difficult life situations is also known.) The conflicts in Bosnia, Sri Lanka, and Somalia in the 1990 s show that those who could not escape from conflict and violence were much more in need of humanitarian assistance than refugees and internally displaced persons [26]. Meanwhile, the situation of forcibly immobilized groups causes much less public resonance and a weaker response from political initiatives than large-scale forced migrations, not to mention the obstacles for representatives of humanitarian organizations to access those who have been trapped, as occurred in Syria under the pandemic. Recall that due to the protracted nature of many political conflicts, the constraints of trapped people are often longer than in situations of natural disasters.

In recent decades, mainly focal forms of forced immobilization have been characteristic, including those associated with restrictions on the movement of the population for medical reasons in the context of the epidemics of SARS, MERS, H1N1, Zika, and Ebola. The COVID-19 pandemic, disrupting the previous algorithms of movement, actually caused a global forced immobility of the population. During the initial period of the pandemic, the massive closure by states of their borders to foreigners and sometimes to their own citizens, the cessation of direct communication between countries, and the widespread introduction of other prohibitive measures were aggravated by the financial and logistical difficulties of returning home for people who were abroad. In many countries, foreign workers who were unable to return to their homeland found themselves in an extremely difficult financial situation because of the loss of jobs and the inaccessibility of social transfers for many of them. The expiration of a temporary visa or residence permit called into question the legality of the residence status of such migrants.

As a result, the pandemic formed a global cohort of so-called stranded migrants. According to the International Organization for Migration, in July 2020 there were more than $2.75 \mathrm{mln}$ of them in the world, including about $1.3 \mathrm{mln}$ in the Middle East and North Africa region, 977000 in the Asia-Pacific region, and 203000 in the European Economic zone and Switzerland [27]. The press also reported about 400000 people stranded due to the pandemic on international seagoing ships.

At the same time, there are differences between people trapped in conflicts and natural disasters and migrants stranded in the trap of the pandemic. In the former case, it is mainly the most vulnerable strata of the local population that are immobilized. In the latter, there are a variety of groups of visitors: foreign seasonal workers and students; persons with temporary residence permits; medical tourists; crews of ships; participants in resettlement, voluntary repatriation, and reintegration programs; and many others. In addition, as noted by the Belgian researcher C. Zickgraf, 
those who are restricted in movement in conditions of political and natural disasters can avoid threats to security and freedom by leaving the respective territory. On the contrary, forcible temporary quarantine of travelers from the countries of the "red list" and those in contact with them, as well as residents of epidemically unfavorable territories, is a way to preserve health and life not only for these but also for broader categories of the population [26]. By and large, the self-isolation regime was rather involuntary. As a result of the lockdown in the spring of 2020, almost half of people on Earth were forced to stay at home, not to mention facing the inability to travel abroad.

The large-scale containment of mobility during the pandemic is evidenced by data from migration statistics. According to the OECD, the number of newly issued visas and other permits to the countries of this organization decreased in the first half of 2020 by $46 \%$ compared to the same period in 2019, including by $72 \%$ in the second quarter of 2020 [28]. The total world number of tourist arrivals in 2020 decreased by $70 \%$ compared to 2019 [29, p. xii]. According to UN estimates, if the pandemic had not happened, perhaps in mid-2020 the cohort of international migrants would have been $2 \mathrm{mln}$ larger, and its growth rate from July 2019 to June 2020 would have been $27 \%$ higher than that recorded [30].

According to materials from the UN High Commissioner for Refugees (UNHCR), at least 72 countries have refused to admit asylum seekers. Thousands of refugees from Latin America were "trapped on the move" [25] in northern Mexico, awaiting a decision by the US authorities in temporary detention camps. Hundreds of Rohingya (an ethnic group in Myanmar) refugees were forced to spend months at sea, unable to land in Malaysia due to anti-COVID restrictions. The suspension of the refugee resettlement program led to the freezing of their flows for at least two months. In the first nine months of 2020 , only 15000 refugees were resettled, compared to 50000 in the same period in 2019. ${ }^{5}$ The impact of the pandemic on the refugee protection system reveals a close connection between forced mobility and immobility, which have begun to complement one another.

Although there is still no systematic accounting of the forced immobilized, the increasing instability of modern development, especially during the pandemic, directly and indirectly indicates that such groups have increased in size. Although with the accumulation of experience in countering the pandemic, prohibitive measures are giving way to permissive measures, the multiplicity of restrictions, of which

\footnotetext{
${ }^{5}$ COVID-19 Analytical Snapshot \#63: Displaced Populations Impacts Update. $23 \quad$ December 2020. https://www.iom.int/sites/default/files/documents/covid19_analytical_snapshot_63_displaced_population_impacts_update.pdf.
}

there were more than 100000 in the spring of 2021; the stringent requirements on the health of travelers, as well as their medical documents; digital control over the movement of people; etc., have created serious obstacles to the resumption of massive population movements, opening the "age of involuntary immobility” [19].

\section{POLITICAL AND LEGAL APPROACHES TO FORCED MOBILITY AND IMMOBILITY}

The transformation of forced migration into an important issue on the international agenda testifies to the acute and urgent need to influence the root causes of the large-scale exodus of the population from their native places. At the same time, it is necessary to expand the scope of international (and national) protection and support and assistance to a larger number of categories and individuals, to develop mechanisms for a prompt and flexible response to migration crises, and to increase the effectiveness of efforts in this area.

Particular attention is paid to refugees. People who meet the definition of refugee under international, regional (EU, African Union, and other documents), or national legislation or under the UNHCR mandate are refugees under international law, regardless of whether they have been officially recognized as such. This applies, for example, to people who are forced to flee from the indiscriminate consequences of armed conflicts.

At the regional and especially international level, in the 2010s, several important documents were adopted that allow expanding the grounds for granting this status. The UNHCR Handbook on Procedures and Criteria for Determining Refugee Status (2011) provides for the application of the definition of refugee to people persecuted on the basis of gender and victims of trafficking and also allows for the interpretation of this definition in relation to sexual orientation and in connection with military service. According to the UNHCR Legal Commentary on the protection of refugees (2017), these standards may apply to people fleeing hunger caused by armed conflict, violence, and earthquakes in countries with undemocratic regimes.

Refugees and asylum seekers are granted certain rights and benefits, including social support. At the same time, incomplete or inconsistent application of legal standards and norms in this area weakens the provision of international protection. The Comprehensive Refugee Response Framework, adopted at the UN General Assembly in 2016 and included in the Global Compact on Refugees 2018, is intended to contribute to the improvement of the situation in this area. A positive impetus to this process can be provided by efforts to ease the burden on host countries; increase the ability of refugees to support themselves; expand their accessibility to third countries; and facil- 
itate their safe and dignified return to their homes. At the same time, from a conceptual point of view, it is not entirely correct to use the terms refugee and migrant in these documents to designate independent, nonoverlapping groups of the mobile population.

Note that the so-called climate, environmental, etc., refugees, who do not have an accepted definition, in fact, "fall into chasms in international humanitarian law" [11, p. 72]. This is especially true for people forced to leave their countries due to the gradual destruction of the environment. Indeed, until recently, international and regional documents (the aforementioned 1998 UN Guiding Principles and the 2009 Kampala Convention of the African Union) mainly dealt with issues related to the displacement of persons for these reasons only within the country. This means that it is urgently necessary to create a special regulatory framework for the recognition of the status and protection of such external migrants, the development and improvement of the functioning of the appropriate institutional structure, and the formation of effective interstate and regional cooperation and agreed responses in this area.

The formation of the legal basis for the protection of this category of migrants was facilitated by the development of UNHCR recommendations (2017) on the use in legal practice of the concept of persons in need of international protection, which is broader than refugees. In addition to refugees, this category includes people moving across international borders due to natural or anthropogenic disasters or the adverse effects of climate change, including rising sea levels, which threaten small island states with flooding and their citizens with a stateless status. For people who are exposed to serious threats but do not fall under the definition of refugees, mechanisms of temporary stay in the host country on humanitarian grounds and other additional protection instruments that regulate the rules of admission and the status of such migrants may be applied.

A landmark document in terms of joint efforts, integrated approaches, and comprehensive measures was the Global Compact for Safe, Orderly, and Regular Migration, signed (albeit nonbinding) in 2018 by more than 150 states. Among the most important actions proposed in its section on environmental issues are the development of adaptation strategies implemented as a priority in the country of origin (which would limit forced cross-border migration) and support for measures that reduce vulnerability and increase the resilience and self-sufficiency of affected people.

This treaty, like the treaty on refugees, fits into the broader context of international efforts. They are aimed at reducing the likelihood of conflicts and natural disasters, increasing the effectiveness of support for victims, creating a culture of civil protection among the population, and taking preventive mea- sures. ${ }^{6}$ Serious attention is paid to the development of resettlement programs, including within the framework of adaptive climate risk management. Future resettlement schemes are designed to ensure the resilience of people and communities to environmental changes with account for anthropogenic pressure and tensions in the labor market and in the field of social services and to reduce the likelihood of interethnic and interfaith conflicts in the host territories.

At the same time, the situation of forcedly immobile people is still outside the proper legal regulation. Meanwhile, back in 1993, the then High Commissioner S. Ogata made a statement about the need to respect and take into account the will of the population of crisis zones, their "right to stay," which inspired the campaign of "preventive protection," launched by the United Nations in the 1990s [25]. The Nansen Initiative also called not to ignore those who continue to be in unfavorable environmental conditions. Experts emphasize the importance of providing people in crisis situations with necessary information to make their choices informed, preventing people from falling into the traps of conflicts and natural disasters, and providing opportunities to leave their foci. Without encouraging those who may not want to relocate to move, it is necessary to create security zones in which immobile groups could benefit from the protection and assistance of the UN and humanitarian organizations [25].

To improve the lot of migrants stranded in the early stages of the pandemic, the IOM launched an initiative to identify their needs for information, consular, and visa support and assistance in repatriation. The governments of the host countries of such foreigners took urgent legal and socioeconomic measures, which were of a short-term and nonsystemic nature [31, 32]. A number of countries of origin of the migrants organized the return of their citizens to their homelands. In the spring of 2020, within the framework of such campaigns, according to various estimates, about 200000 Russians, 600000 residents of the EU countries, 145000 Filipinos, and 77000 Egyptians returned home. ${ }^{7}$

\footnotetext{
${ }^{6}$ Important agreements include the 2015 Agenda for Sustainable Development, the Paris Agreement on Climate Change, and the Sendai Framework for Disaster Risk Reduction 2015-2030. Consultative processes include the Nansen Initiative, launched in 2012 and reformed in 2016 into the Platform on Disaster Displacement; IOM Migrants in Countries in Crisis Initiative and Guidelines for Protecting Migrants in Conflict and Natural Disasters (2016); and the Global Platform for Disaster Risk Reduction (2017)

${ }^{7}$ COVID-19 Analytical Snapshot \#54: Returning Migrants UPDATE. $\quad$ September 2020. https://www.iom.int/sites/default/files/documents/covid19_analytical_snapshot_54-_returning_migrants_update.pdf.
} 
Forced mobility and immobility, personifying directly opposite options of migration behavior, i.e., action and inaction, are related concepts and interrelated processes and states generated by the same or similar causes. Political and environmental cataclysms increase the cohorts of the population forced to displace, which relay the trouble and instability from one region to another. The proliferation of hot spots of conflict and disasters increases the risks of getting stranded in the traps of immobility for large groups of people. The increase in the scale of forced displacements and in the proportion of refugees and asylum seekers among migrants indicates the intensification of the forced nature of modern migration. In the long term, this trend can be strengthened by a weakening of voluntary migration with the spread of forced immobility of the population, including against the background of a high probability of new pandemics. The digitalization of the economy contributes to the decline in mobility, leading to a reduction in the need for low-skilled foreign labor and the replacement of physical migration of specialists with a virtual one.

While the root causes of forced displacement and immobility persist, measures to improve the situation of those affected by political and environmental disasters are often palliative. Nevertheless, there is a tendency to expand the scope of protection and assistance to broader categories of people who need them. With regard to refugees and internally displaced persons, whose position is regulated by a large number of normative documents, it is important to improve law enforcement mechanisms. The status of migrants leaving their homeland for environmental, including climatic, reasons, needs a clearer definition at the level of an international convention. It is necessary to develop standards for the protection and support of people trapped in conflicts and disasters. The growing focus of interested parties on making complex decisions and implementing joint actions gives hope for progress in developing effective and proactive responses to the challenges of forced mobility and immobility.

\section{REFERENCES}

1. Global Peace Index 2020 Briefing: Measuring Peace in a Complex World (Institute for Economics \& Peace, Sydney, 2020). https://www.visionofhumanity.org/wpcontent/uploads/2020/10/GPI_2020_Briefing_Web.pdf. Cited March 5, 2021.

2. World Migration Report 2020 (IOM, Geneva, 2019).

3. J. Urry, Mobolities (Polity, Cambridge, 2012).

4. E. Piguet, "Theories of voluntary and forced migration," in Routledge Handbook of Environmental Displacement and Migration, Ed. by R. McLeman and F. Gemenne (Routledge, New York, 2018), pp. $17-28$.
5. S. Castles, "Towards a sociology of forced migration and social transformation," Sociology, No. 37, 13-34 (2003).

6. N. Van Hear, "Theories of migration and social change," J. Ethn. Migr. Stud. 36 (10), 1531-1536 (2010). https://doi.org/10.1080/1369183X.2010.489359

7. S. Castles, "Understanding global migration: A social transformation perspective,” J. Ethn. Migr. Stud. 36 (10), 1565-1586 (2010).

8. R. Black, S. Bennett, S. Thomas, and J. Beddington, "Migration as adaptation," Nature 478, 447-449 (2011).

9. A. Betts, "Survival migration: A new protection framework," Glob. Gov., No. 3, 361-382 (2010).

10. International Migrant Stock 2020 (United Nations database, POP/DB/MIG/Stock/Rev.2020) (UNDESA, PD, 2020).

11. Yu. V. Zvorykina and K. S. Teteryatnikov, "Climatic (or ecological?) migration: Problems and prospects," Tr. VEO Ross., No. 2, 237-256 (2019).

12. Frontiers 2017: Emerging Issues of Environmental Concern (UNEP, Nairobi, 2017).

13. Glossary on Migration (IOM, Geneva, 2019).

14. V. I. Evtushenko, "Environmental migration as an integral part of the system of human protection and ensuring environmental safety," Lex Russica, No. 6, 158169 (2016).

15. A. V. Topilin, Population Migration and the Formation of Labor Resources in the USSR and the Post-Soviet Space: Trends and Regulation (Ekon-Inform, Moscow, 2020) [in Russian].

16. Global Internal Displacement Database. https://www.internal-displacement.org/database/displacement-data. Cited May 29, 2021.

17. Tomorrow's World of Migration (FES, Global Future, IOM, Geneva, 2017).

18. K. Rigaud, A. de Sherbinin, B. Jones, et al., Groundswell: Preparing for Internal Climate Migration (World Bank, Washington, DC, 2018).

19. J. Carling, "Migration in the age of involuntary immobility: Theoretical reflections and Cape Verdean experiences,” J. Eth. Migr. Stud. 28 (1), 5-42 (2002).

20. K. Schewel, "Understanding immobility: Moving beyond the mobility bias in migration studies," Int. Migr. Rev. 54 (2), 328-355 (2020). https://doi.org/10.1177/0197918319831952

21. Foresight. Migration and Global Environmental Change: Future Challenges and Opportunities. Final Project Report (Government Office for Science, London, 2011). https:www.gov.uk/government/publications/migration-and-global-environmental-changefuture-challenges-andopportunities. Cited April 3, 2021.

22. H. Haas, "Migration theory Quo Vadis?," IMI Working Papers Series, No. 100, 1-39 (2014). https://www.migrationinstitute.org/publications/wp100-14. Cited May 1, 2021.

23. J. Schon, "Violent encounters and social status shape the conditions for migrants fleeing civil war," Migration Information Source, Mar. 4 (2021). https://www.mi- 
grationpolicy.org/article/conditions-migrants-fleecivil-war-syria. Cited April 23, 2021.

24. S. Ayeb-Karlsson, D. Kniveton, and T. Cannon, "Trapped in the prison of the mind: Notions of climate-induced (im)mobility decision-making and wellbeing from an urban informal settlement in Bangladesh," Palgrave Communications 6, Article no. 62 (2020). Cited April 23, 2021. https://doi.org/10.1057/s41599-020-0443-2

25. R. Black and M. Collyer, "Populations 'trapped' at times of crisis," Forced Migr. Rev., No. 45, 52-56 (2014).

26. C. Zickgraf, Were we all trapped? Reflections on immobility during a global pandemic. https://environmentalmigration.iom.int/blogs/were-we-all-trappedreflections-immobility-during-global-pandemic. Cited April 3, 2021.

27. "COVID-19 impact on stranded migrants," Return Task Force, Oct. 8 (2020). https://www.iom.int/sites/default/files/documents/issue_brief_return_task_force.pdf. Cited May 1, 2021.

28. International Migration Outlook 2020 (OECD Publishing, Paris, 2020).

29. World Economic Situation and Prospects 2021 (UN, New York, 2021).

30. International Migration $2020 \quad$ Highlights (ST/ESA/SER.A/452) (UNDESA, PD, 2020).

31. S. V. Ryazantsev, A. D. Bragin, and N. S. Ryazantsev, "The situation of labor migrants in regions of the world: Challenges of the COVID-19 pandemic and the response of governments," Nauch. Obozr., Ser. 1: Ekon. Pravo, No. 3, 7-21 (2020).

32. Welfare State in the Mirror of Social Transformations, Ed. by E. S. Sadovaya, I. P. Tsapenko, and I. V. Grishin (IMEMO RAN, Moscow, 2020) [in Russian].

Translated by B. Alekseev 